\title{
Help seeking behavior in patients with alcohol dependence in a tertiary care hospital in eastern Nepal
}

\author{
Shakya DR ${ }^{1 *}$, Shyangwa PM ${ }^{2}$, Sen B $^{2}$ \\ Address: 1. Associate professor, Department of Psychiatry ,B P Koirala Institute of Health Sciences, Dharan, Nepal , 2. \\ Professor, Department of Psychiatry, B. P. Koirala Institute of Health Sciences, Dharan, Nepal.
}

E-mail*Corresponding author: drdhanashakya@yahoo.com

Abstract

Introduction: Though alcohol problem is common in Nepal, fewer patients seek help. Current study aims to see help seeking behavior among alcohol dependence syndrome (ADS) cases admitted in psychiatry ward of B P Koirala Institute of health sciences, Dharan, Nepal.

Method: All ADS cases admitted in the psychiatry ward in 12 month period (2004/5) were enrolled. It is a descriptive study using the 'International classification diseases and infermities' (ICD)- $10^{\text {th }}$ edition as a diagnostic tool and semi-structured proforma to collect information about clinicodemography and help seeking.

Results: Out of total $51,82 \%$ were male. Only 3 cases came solely to quit drinking. Common presentations at admission were behavioral problems (39.2\%), restlessness (37.3\%) and disturbed sleep (27.5\%). Most were brought by family members (43\%); some referred by other departments and some others by paramedical, rehabilitatiun centres and traditional healers. Thirty five cases $(68.6 \%)$ did not consider drinking as a problem. Thirteen percents were receiving treatments from other places. Poverty and conservative attitude in $10 \%$ each were other reasons for treatment delay. Before reaching this service, $96 \%$ had used some home remedies, $23.5 \%$ visited traditional healers and $12 \%$ local drug stores. Fifty nine percents had received services from 2 or less other places before reaching the psychiatrist for recent problem whereas $41 \%$ had 3 or more.

Conclusion: The main reason for delay in help seeking for ADS in Nepal is the lack of realization that drinking and its consequences are at all any problem.

Key words: alcohol, alcohol dependence, BPKIHS, help seeking, psychiatric in-patients

\section{INTRODUCTION}

Alcohol dependence sydrome (ADS) is common in community $^{1-3}$, more so in eastern part of Nepal. ${ }^{4-5}$ ADS cases usually do not visit psychiatric service. ${ }^{6}$ When they present to psychiatric service, they usually have higher rates of both physical ${ }^{7}$ and psychiatric comorbidities ${ }^{8}$ and they are likely to present as psychiatric emergencies. ${ }^{9}$ Despite of a great magnitude and burden of the problem, there is a scarcity of data about help seeking in ADS from this part of Nepal.

Current study was carried out in the period of 12 months (July, 2004 - June, 2005) in the department of Psychiatry, B P Koirala Institute of health sciences (BPKIHS), Dharan, Nepal to explore into help seeking behavior among ADS cases by the time of psychiatry ward admission. Overarching objective would be to identify the bariers of help seeking process and strategies to overcome them.

\section{METHODS}

It is a descriptive cross sectional study in consecutive inpatients with ADS diagnosed according to the ICD-10 criteria. ${ }^{10}$ It was carried out among all 51 consecutive consenting cases of ADS admitted in psychiatry ward of
BPKIHS, Dharan, Nepal within 12 month period of data collection from July, 2004 to June, 2005.

The study was approved by the institute ethical review board. Informed written consent was collected from the subjects. Strict confidentiality of information was maintained. The information was utilized for the appropriate management of the cases concerned and similar cases in general, and for the research.

All patients with significant medical complications making them unable to be interviewed were excluded from this study.

Information on different aspects of help seeking behavior and relevent demographic and clinical profiles were collected using the semi structured proforma which was designed and approved by the department. The proforma consisted of and in all cases, an endeavor was made to investigate into and record:

1. The possibly relevent factors (demographic- age, gender, education, marital status; geographical/ socialresidential setting, accessibility to the hospital), 
2. Clinical variables (presenting complaints, referral sources),

3. Subject's/ responder's view about 'reasons for treatment delay, and

4. Pathway to current service.

Data were entered into a computer and analyzed using the 'Statistical Package for Social Science' (SPSS) - software.

\section{RESULTS}

Out of total of 51 cases, nine (18\%) were female and 42 $(82 \%)$ male (see table 1). The maximum numbers of cases were in the age group of $30-40(43 \%)$ and $40-50$ years $(33 \%)$. The mean age of the patients was 39.65 years (Minimum 25, maximum 65, Standard deviation 8.68). A great majority of the cases $45(88 \%)$ were married and some were separated $3(5.9 \%)$. Most of the cases were either from joint family $23(45 \%)$ or nuclear $22(43 \%)$, and others extended $7.8 \%$ and broken $4 \%$.

* Multiple response categories-One respondent may have one or more responses.

Table 1: Socio-demographic profiles I: Gender, Age, Marital status and family type.

\begin{tabular}{|l|c|}
\hline \multicolumn{1}{|c|}{ Gender } & No. of cases (\%) \\
\hline Male & $42(82)$ \\
Female & $9(18)$ \\
\hline Age group (years) & \\
\hline$<30$ & $4(7.8)$ \\
$30-39$ & $22(43.1)$ \\
$40-49$ & $17(33.4)$ \\
$50-60$ & $6(11.8)$ \\
$>60$ & $2(3.9)$ \\
\hline Marital status & \\
\hline Married & $45(88.22)$ \\
Single & $2(3.9)$ \\
Separated & $3(5.9)$ \\
Widow & $1(2.0)$ \\
\hline Family type & \\
\hline Nuclear & $22(43.1)$ \\
Joint & $23(45.1)$ \\
Extended & $4(7.8)$ \\
Broken & $2(4.0)$ \\
\hline
\end{tabular}

As per table 2 Common castes among the help seekers were: Rai, the most 15 (29\%), Brahmin, Chhetri, Limbu, Tamang, Newar, and Magar. About $80 \%$ were traditional users.

Among them, Hindus (including Kirantis) were $78 \%$ and Buddhists $16 \%$. About $84 \%$ were educated to different levels and only $16 \%$ illiterate.

Majority (78\%) were employed in different professions and $22 \%$ currently unemployed.

Two thirds of the cases $34(66.7 \%)$ were of middle socioeconomic status.
Table 2: Socio-demographic profiles-II: Caste/ ethnicity, Religion, Education, Occupation and socioeconomic status

\begin{tabular}{|l|c|}
\hline Caste & No. of cases (\%) \\
\hline Rai & $15(29.4)$ \\
Brahmin & $10(19.6)$ \\
Chhetri & $8(15.7)$ \\
Limbu & $5(9.8)$ \\
Newar & $4(7.8)$ \\
Tamang & $4(7.8)$ \\
Magar & $1(2.0)$ \\
Others & $4(7.8)$ \\
\hline Religion & \\
\hline Hindu & $40(78.4)$ \\
Buddhist & $8(15.7)$ \\
Muslim & $1(2.0)$ \\
Christian & $1(2.0)$ \\
Others & $1(2.0)$ \\
\hline Educational status & \\
\hline Illiterate & $8(15.7)$ \\
Grade I-III & $4(7.8)$ \\
Grade IV-VII & $13(25.5)$ \\
Grade VIII- SLC & $15(29.5)$ \\
Intermediate & $5(9.8)$ \\
Graduate & $3(5.9)$ \\
Higher & $3(5.9)$ \\
\hline Occupation & \\
\hline Business & $7(13.7)$ \\
Agriculture & $6(11.8)$ \\
Labor & $1(2.0)$ \\
Service & $9(17.6)$ \\
House making & $4(7.8)$ \\
Teaching & $3(5.9)$ \\
Unemployed & $11(21.6)$ \\
Others & $10(19.6)$ \\
\hline Socio-economic status & \\
\hline Lower & \\
Middle & \\
Upper & $(7.8)$ \\
\hline
\end{tabular}

Almost half were from urban and rural settings each as per the data in table 3.Nearly half of the cases were from the readily accessible places, $29.4 \%$ from far but accessible and $23.5 \%$ from the places with no facility of transportation.

Table 3: Residential setting and accessibility to the hospital

\begin{tabular}{|l|l|}
\hline Residential setting & No. of cases (\%) \\
\hline Rural & $25(49)$ \\
Urban/Dharan & $26(51)$ \\
\hline Accessibility to the hospital & \\
\hline Readily accessible & $24(47.1)$ \\
Accessible & $15(29.4)$ \\
Far & $12(23.5)$ \\
\hline
\end{tabular}




\section{Figure1: Presenting complaints}

Only one third of the cases realized drinking as a problem. Among common presentaions at the time of admission were: behavioral problems $(39.2 \%)$, restlessness $(37.3 \%)$ and $27.5 \%$ disturbed sleep.

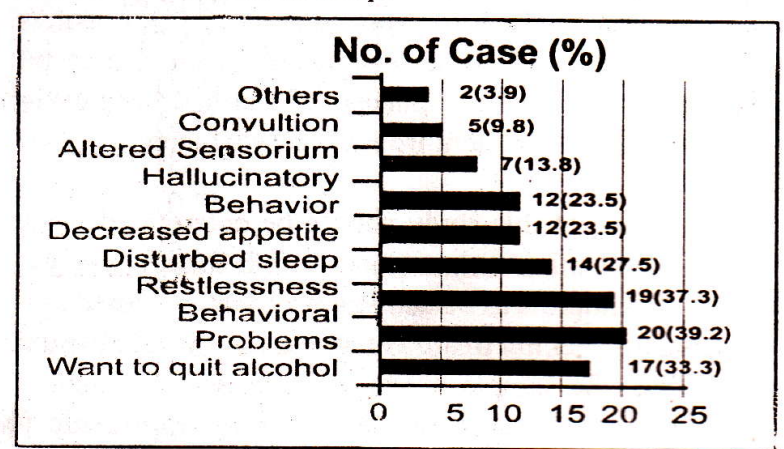

Table 4: Sources of Referral

\begin{tabular}{|l|c|}
\hline Source of referral & Frequency (\%) \\
\hline Self & $6(11.8)$ \\
\hline Family members & $22(43.1)$ \\
\hline Relatives/ neighbors & $9(17.6)$ \\
\hline Alternative/ traditional & $2(3.9)$ \\
\hline Paramedics & $2(3.9)$ \\
\hline Other doctors & $8(15.7)$ \\
\hline Rehab. Center & $1(2.0)$ \\
\hline Others & $1(2.0)$ \\
\hline
\end{tabular}

As mentioned above only $12 \%$ came themselves. Most cases $(43.1 \%$ ) were brought by family members or $(17.6 \%)$ by relatives or neighbors and $15.7 \%$ referred by other doctors/ specialists.

Table 5: Reasons of delay in treatment

\begin{tabular}{|l|l|}
\hline Reasons & No. of case (\%) \\
\hline Not took as problem & $35(68.6)$ \\
\hline Not knew about treatment & $9(17.6)$ \\
\hline Treating elsewhere & $7(13.7)$ \\
\hline Conservative attitude & $5(9.8)$ \\
\hline Lack of money/ poverty & $5(9.8)$ \\
\hline Distance from hospital & $1(2.0)$ \\
\hline Others & $1(2.0)$ \\
\hline
\end{tabular}

Many of the patients (68.6\%) did not take it as a problem, $17.6 \%$ did not know about the treatment facility and $9.8 \%$ cases did not come because of poverty and conservative attitude each.

Table 6: Treatment strategies used before reaching the current service

\begin{tabular}{|l|l|}
\hline Category level & No. of cases (\%) \\
\hline Home remedy & $49(96.1)$ \\
\hline Traditional, e.g. Dhami & $12(23.5)$ \\
\hline Medical stores & $12(23.5)$ \\
\hline Ayurved/ homeo & $2(3.9)$ \\
\hline PHC/ nursing home & $8(15.7)$ \\
\hline Secondary/ rehab. centre & $6(11.8)$ \\
\hline Other tertiary center & $4(7.8)$ \\
\hline
\end{tabular}

Most people had adopted one or other method before- $96 \%$ some home remedy, $23.5 \%$ visited traditional healers and medical stores each, $15.7 \%$ PHC or nursing home, $11.8 \%$ secondary treatment centre or rehabilitation centre.

Figure 2: Number of other help seeking steps of pathway in reaching to BPKIHS

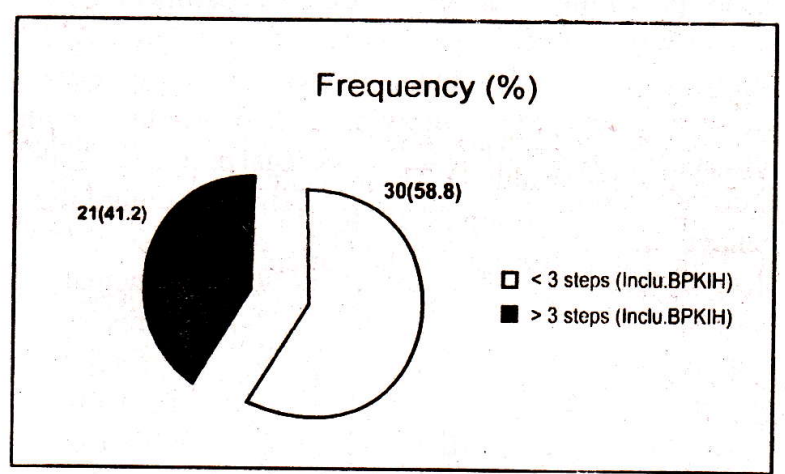

Nearly $60 \%$ of the individuals had presented to BPKIHS in third or less than third step of help seeking pathway for recent health problem related to alcohol use.

\section{DISCUSSION}

In context of Nepal, drinking : s socially acceptable in most of the sub-cultures. People are poor, less educated and do not always have access to proper health facilities. Although there have been few studies on this regard, it is evident that there are many barriers preventing problem drinkers from reaching the health care facility, like BPKIHS. Alcohol problems are much more widely spread in the community than are presented clinically. ${ }^{6,11}$ People with alcohol dependence do not perceive themselves as disabled and do not seek help. It would be beneficial to address this population so that more of them will seek help.

Most of the research done on the process of help seeking among problem drinkers so far have focused on characteristics of persons with an alcohol problem and the factors affecting their help seeking behavior ${ }^{12,13,14}$ as well as the triggers and barriers to treatment entry. ${ }^{15,16}$

In this study, we tried to see the individual/ personal characteristics of study subjects especially sex, educational status, place of domiciles and residential settings, marital status and socio-economic status. We categorized the subjects into two groups only, because of small sample size. First group consists of those $(58.8 \%)$ presenting to this tertiary care hospital after visiting two or less than two other healing systems or help seeking steps. Second one consists of those ( $41.2 \%)$ presenting after consulting three or more other treatment systems. Assuming that the first one represents earlier treatment entry than the later, we did not find any statistically significant difference in different socio-demographic variables: sexes, educational levels, the place of domiciles and settings, marital status and socio-economic status. Our study was carried out in the subjects from inpatients who presented mainly because of some other serious problems. There was no modern treatment alternative for those individuals in that situations 
but to attend the nearest possible treatment facility. Perhaps because of these factors, we did not get any statistically significant difference in above mentioned sociodemographic variables from the perspective of help seeking.

While presenting to the service of this department, only 3 cases came with the sole purpose of quitting drinking. Many had one or other, medical/ physical $^{7}$ or psychiatric co-morbidities. ${ }^{8}$ Many individuals had problems with interpersonal relationship and some legal problems. At the time of presentations, they had different complains: behavioral problems (about 40\%), restlessness (37\%), sleep disturbance $(28 \%)$, anorexia (24\%), hallucinatory behavior $(24 \%)$, altered sensorium $(14 \%)$, seizures $(10 \%)$ and others $(4 \%)$. This pattern of reporting problem at presentation (rather than problem drinking itself) is consistent with the earlier findings of Proudfoot et al, $2002 .{ }^{17}$ Only one third of the cases wanted to quite alcohol for their problem at presentation even though those added problems were related to alcohol consumption.

Most of the cases in this study i.e. nearly $70 \%$ did not perceive themselves as having problem before developing some complications. They did not consider habitual drinking as a problem and nor did they seek help. Only 6 $(11 \%)$ cases had come themselves. Nearly half were brought by family members and $18 \%$ by relatives. As this is a general hospital, many of the individuals (16\%) had already been seen by other specialists/ doctors before referring them to psychiatric service, similar finding was also observed in earlier study about psychiatry referral. ${ }^{18}$ One case was referred by a staff of rehabilitation center and other one by authority agency, i.e. police department. Hingson et al's study in 1982 on problem drinkers reported that they were generally referred by friends and relatives to different services. ${ }^{14}$ In our study, along with friends and relatives, vast majority of cases were brought to service by family members themselves because of some serious complications. We have less people referred from alcoholic anonymous or rehabilitation centers ( $2 \%$ only) than Hingson et al had ( $29 \%$ and $33 \%$ respectively) which is probably due to lack of these networks in this region.

In this study, we tried to ascertain the help seeking pathway before reaching to this hospital. Thirty cases $(59 \%)$ had sought service from one or two healing settings for the presenting problem. About $41 \%$ had utilized service of three or more of other services. This number is more than the finding of Hingson et al 1982 (33\% utilizing multiple helps). ${ }^{14}$ Forty nine cases $(96 \%)$ had used one or other forms of home remedy, e.g. herbal, ritualistic measures. Twelve patients $(23.5 \%)$ had visited traditional healing systems like Dhami, Jhankris and only 2 cases homeopathy or Ayurveda. Only less proportion of cases visiting these laternative healers may be because of the fact that they were mostly from the areas around the hospital and by that time they had already developed some serious complications.?
Eighteen percent cases reported that they were not aware of the treatment facility, $10 \%$ had negative attitude towards modern measures for this problem and preferred other alternative methods, and $10 \%$ had difficulty with affordability and some other cited the distance as barrier to seeking help from this tertiary care hospital. Four cases $(14 \%)$ had been referred or from other tertiary care centers. Most of them were from around the hospital area but working in other towns/ places. ${ }^{19}$ So, it had been easier for them to get treatment from their own place.

The findings of this study should be entertained in the light of some inherent limitations, i.e. 1. Sample size was small, 2. Sample was biased in a way that it studied only the patients seeking treatment at a tertiary level hospital. Therefore, the sample might not represent the general population and the results may not be applicable to community. Hence, further community based studies are recommended for more information.

\section{CONCLUSION}

Many of problem drinkers do not seek help. They present to psychiatric service late when they have complications. The main reason for delay in seeking help for ADS is lack of realization that drinking and its consequences are at all any problem. Hence, public awareness regarding $\mathrm{ADS}$ should be raised in different levels through various sound programs

\section{REFERENCE}

1. World Health Organization. WHO Report 2000-Mental Health: New Understanding: New Hope. 2001. Geneva.

2. Schuckit MA. Alcohol Related Disorders. In: Sadock BJ and Sadock VA eds. Comprehensive Textbook of Psychiatry, $8^{\text {th }}$ Edition, 2002. Lippincott Williams and Wilkins. Philadelphia. Pp 1168-88.

3. Royal College of Psychiatrists. A Historical Perspective. Alcohol: Our Favorite Drug. 1986. London, Tavistock. Pp 11.

4. Jhingan HP, Sharma A, Koirala S, Shyangwa P, Upadhyay M, Prasad KMR and Khandelwal SK. Prevalence of alcohol dependence in a town in Nepal as assessed by CAGE questionnaire. Addiction, 1998; 339-43.

5. Shyangwa PM and Shakya DR. Substance Use in Eastern Nepal: Current Situation, Response and Future Strategy. In: Souvenir of the $2^{\text {nd }}$ International Conference of SAARC Psychiatric Federation, November, 2006. Kathmandu. Pp 38-9.

6. Ramachandran V. Presidential Address- The Prevention of Alcohol-Related Problems. Indian Journal of Psychiatry, 1991; 33(1). 
7. Shakya DR, Shyangwa PM, Sen B. Physical diseases in cases admitted for alcohol dependence. Health Renaissance. 2008; 5(1):27-31.

8. Shakya DR, Shyangwa PM, Sen B. Psychiatric comorbidity in cases admitted for alcohol dependence. Delhi Journal of Psychiatry. 2009; 12(2):252-257.

9. Shakya DR, Shyangwa PM, Shakya R. Psychiatric emergencies in a Tertiary care Hospital. J Nepal Med Assoc. 2008; 47(169): 28-33.

10. World Health Organization. The ICD-10 Classification of Mental and Behavioral Disorders Diagnostic Criteria for Research. WHO. Geneva. 1993.

11.Regmi SK, Khalid A, Pokharel A. Psychiatric morbidity Profile of Patients Attending Psychiatric OPD, TUTH. In: Souvenir of $1^{\text {st }}$ National Congress of Psychiatrists' Association of Nepal, 1998. Department of Psychiatry, BPKIHS.

12.Sanders TB. Changing Perspectives on Alcohol and Drug Problems. Australian Alcohol \& Drug Review. 1986; 5:41-45.

13.Room R, Babor T, Rehm J. Alcohol and Public Health. The Lancet. 2005; 365:519-528.

14.Hingson R, Mangione T, et al. Seeking Help for Alcohol Problems: A Study in Boston Metropolitan Area. Journal of Studies on Alcohol. 1982; 43:273-288.

15. Thom B. Sex Differences in Help Seeking for Alcohol Problems 1. The Barriers to Help Seeking. British Journal of Addiction, 1986; 81:777-788.

16.Jordan CM, Oei TPS. Help Seeking Behavior in Problem Drinkers: A Review. British Journal of Addiction. 1989; 84:979-988.

17.Proudfoot H. Who Seeks Treatment for Alcohol Dependence? Findings from Australian National Survey of Mental Health and Wellbeing. Soc.Psychiatry. 2002; $37(10): 451-56$.

18. Shakya DR, Pandey AK, Shyangwa PM, Shakya R. Psychiatric morbidity profiles of referred Psychiatry OPD patients in a general hospital. Indian Medical Journal. 2009 Dec; 103(12): 407-411.

19. Shyangwa PM, Lamichhane N, Shakya R, Shakya DR, Sapkota N. Psychiatry morbidity in foreign job holders. Journal of Gandaki Medical College. June 2009; 2(2):45-52. 